\title{
¿LA CREATIVIDAD \\ O LA "RECREACIÓN" \\ FRASEOLÓGICA? \\ ACERCA DEL PROCESO \\ DE DESAUTOMATIZACIÓN \\ Y DE MODIFICACIÓN \\ FRASEOLÓGICAS
}

\author{
Agnieszka Gwiazdowska \\ Universidad de Silesia de Katowice \\ http://dx.doi.org/10.18778/8220-201-4.10
}

\section{Resumen}

Como señalan Corpas Pastor y Mena Martínez (2003: 181), la fraseología parece exenta de creatividad y suele considerarse una parcela eminentemente estable de las lenguas hasta el punto de merecer adjetivos como fosilizado, congelado, prefabricado, etc. En el presente artículo indagaremos en el fenómeno de la desautomatización o manipulación fraseológica, que sigue suscitando el interés de muchos fraseólogos, y lo contrastaremos con otro proceso lingüístico: la modificación fraseológica. Intentaremos demostrar que a pesar de estar estrechamente vinculados, ambos fenónemos no producen los mismos efectos en el discurso y no siempre desencadenan la creatividad o el ingenio, de ahí que no puedan tratarse indistintamente.

Palabras clave: Creatividad fraseológica, desautomatización fraseológica, modificación fraseológica, deslexicalización, variabilidad. 


\section{1.}

\section{Aspectos preliminares}

El presente trabajo expone algunas reflexiones y consideraciones teóricas acerca de la naturaleza y los objetivos de dos procesos lingüísticos que han suscitado un gran interés en los últimos años en el campo de la fraseología, particularmente en el de la fraseopragmática: el fenómeno de la desautomatización y de la modificación fraseológicas.

En las líneas que siguen, tomando como punto de partida las investigaciones de Corpas Pastor (1996), Ruiz Gurillo (1997), Mena Martínez (2003), Timofeeva (2009), entre otros, nos centraremos en la vertiente no canónica de las unidades fraseológicas (en adelante, UF). Pretenderemos analizar y contrastar los fenómenos mencionados, gracias a los cuales el significado fraseológico "supuestamente fosilizado de pronto se convierte en la materia prima para nuevas creaciones lingüísticas" (Timofeeva, 2009: 249). Por un lado, ofreceremos una perspectiva general de la modificación y de la desautomatización, vinculándolas con otras características fraseológicas como la fijación y la variabilidad. Por otro lado, nos adentraremos en sus distintas manifestaciones y tipos, esto es, presentaremos algunas particularidades de su funcionamiento y efectos que pueden producir en el contexto comunicativo. Partiremos del supuesto de que ambos conceptos no pueden tratarse indistintamente, como nociones sinónimas, ni pueden confundirse con otros fenómenos fraseológicos como variantes, variaciones, desviaciones lingüísticas. A lo largo del presente artículo intentaremos responder a estas preguntas clave: ¿Tanto el proceso de desautomatización como el de modificación despliegan la creatividad fraseológica o, más bien, son simples recreaciones fraseológicas?, ¿En qué se diferencian y en qué coinciden dichos fenómenos?

Una vez presentados los objetivos del presente trabajo conviene hacer una puntualización más: existe una gran confusión terminológica a la hora de definir esta vertiente no canónica del hecho fraseológico. Zuluaga Ospina (2001), Timofeeva (2009), Ruiz Gurillo (1997), Mena Martínez (2003) la denominan 
desautomatización, García-Page Sánchez (1989) recurre a la noción de deslexicalización, Corpas Pastor y Mena Martínez (2003) hablan de la manipulación creativa, mientras que González Calvo (2007) la considera neologismo fraseológico ${ }^{1}$. En el presente artículo emplearemos indistintamente los términos desautomatización o manipulación, los cuales serán explicados con más detalle en los apartados siguientes y contrastados con el fenómeno de la modificación fraseológica.

\section{2.}

\section{Acerca de la fijación y variabilidad fraseológica}

Al abordar la cuestión de la desautomatización y la modificación fraseológicas no se puede prescindir de una consideración preliminar: ambos procesos están estrechamente vinculados con dos características principales de las UF: la reproducción que conduce a la fijación -tanto interna como externa- y la variabilidad, que actúan en varios niveles y grados.

Corpas Pastor y Mena Martínez (2003: 182-183) opinan que la estabilidad formal parece ser un elemento inherente a la variabilidad fraseológica y consideran la fijación fraseológica no como una característica absoluta, sino como una propiedad relativa y variable: "la variabilidad se hace posible justamente porque las UF tienen una forma estable y unas marcas bien definidas". Además, según las lingüistas mencionadas, una de las manifestaciones de variabilidad es la ya mencionada modificación. Una opinión

1 Como observa Ruiz Gurillo (1997: 23), el fenómeno de desautomatización también se ha considerado "como un recurso de intertextualidad (Burger 1991) o de polifonía textual (Grésillon y Maingueneau 1984), puesto que la manipulación de una estructura fijada ocasiona varias lecturas posibles de un mismo sintagma o enunciado al tiempo que desencadena todo un conjunto de relaciones y evocaciones".

¿La creatividad o la "recreación" fraseológica?... 
parecida la presenta Dobrovol'skij (1988: 159), quien concibe la variación fraseológica como un universal lingüístico que permite medir el grado de regularidad de un sistema fraseológico dado: cuantas más variaciones, transformaciones o modificaciones presenten las UF de una lengua, más regular es su sistema fraseológico. Burger et al. (1982: 67) también señalan que la fijación y la variación fraseológicas no se consideran rasgos excluyentes, sino complementarios. Ruiz Gurillo (2001: 16-20) añade que la defectividad es una parte integrante de la fijación e, incluso, su simple consecuencia.

A la luz de lo expuesto, podemos constatar que la variabilidad fraseológica es una categoría heterogénea, un fenómeno que "da cabida a múltiples manifestaciones que resultan de diferentes motivaciones e intencionalidades así como de diversos mecanismos lingüísticos" (Corpas Pastor y Mena Martínez, 2003: 184), como variantes sistemáticas o institucionalizadas, variaciones y modificaciones ocasionales.

Tampoco es de extrañar que los distintos tipos de fijación se vean implicados en el fenómeno de manipulación o desautomatización fraseológica que refleja la creatividad de este tipo de lenguaje, tradicionalmente considerado fijo, congelado, exento de creatividad.

\section{3.}

\section{La desautomatización y la modificación frente a la desviación y variación}

Antes de presentar la relación existente entre la desautomatización y la modificación fraseológicas, convendría dedicar unas cuantas palabras a la cuestión de la desviación de la norma fraseológica, con la cual dichos procesos se suelen confundir. Como ya ha sido mencionado, las desviaciones hacen referencia al uso incorrecto de una UF y, a veces, se deben a la contaminación fraseológica, es decir, la mezcla de dos UF como sudar la tinta 
gorda (sudar la gota gorda + sudar tinta) ${ }^{2}$. Mena Martínez (2003), comparando las UF desautomatizadas con las desviaciones y las variantes fraseológicas, corrobora que:

Con las desviaciones tienen en común ser producciones no estandarizadas, no inventariadas, pero a diferencia de las desviaciones, las unidades fraseológicas desautomatizadas son realizaciones conscientes y voluntarias. Por ello, el contexto y cotexto que rodea a la unidad son imprescindibles para discernir si se trata de una desviación o de desautomatización. La desautomatización también puede ser confundida con las variantes. [...] A diferencia de las unidades que presentan desautomatización, las variantes son unidades institucionalizadas e inventariadas, por lo que deberían aparecer en los diccionarios especializados.

Según García-Page Sánchez (2008: 261), las formas desautomatizadas tampoco se pueden confundir con los simples lapsus linguae, dado que son fruto de manipulaciones conscientes y calculadas, diseñadas en función de los propósitos persuasivos del hablante.

Martí Sánchez (2014: 97), por su parte, presenta un punto de vista diferente. Concibe el proceso de desautomatización de una manera más amplia, puesto que aparte de una desautomatización intencionada y voluntaria, la que considera dominante o central, señala la existencia de una desautomatización periférica, espontánea, no intencional y no ostensiva que "comparte con la intencional la reformulación de una UF que vuelve a esta más y más conscientemente usada”. Según el investigador mencionado, dicha desautomatización inintencional es sólo de manera indirecta una reacción contra la automatización y abarca los errores lingüísticos, muy a menudo cómicos tipo, ${ }^{*}$ destornillarse de risa (por desternillarse de risa) o ${ }^{*}$ nadar en la ambulancia (nadar en la abundancia), tradicionalmente considerados desviaciones. A nuestro modo de ver, estas producciones lingüísticas de

2 El ejemplo ha sido extraído de Mena Martínez (2003).

¿La creatividad o la "recreación" fraseológica?... 
carácter espontáneo e involuntario, que surgen en la mayoría de los casos por falta de competencia fraseológica del emisor o debido a la inmediatez del discurso, no presentan ninguna intención de manipulación ni adquieren un significado nuevo. Por ello, no pueden considerarse muestras de creatividad fraseológica (UF desautomatizadas), sino que son simples equivocaciones lingüísticas que "no pertenecen con todo derecho a la variabilidad" (Mena Martínez, 2003).

\section{4. \\ La desautomatización y la modificación fraseológicas: semejanzas y diferencias}

Tal y como hemos mencionado en las líneas anteriores, el fenómeno de la modificación parece estar estrechamente vinculado con el rasgo de fijación fraseológica, no está reñido con la estabilidad, tanto semántica como formal, sino que, en cierto sentido, depende de esta y del conocimiento previo de las unidades originales que les sirven de base (Corpas Pastor, 1996: 233): "cuanto mayor es su fijación, y por ende su institucionalización, más posibilidades hay de que sufran modificación en el discurso, y de que tal modificación y su efecto sean reconocidos por los hablantes" (op. cit.: 29).

Corpas Pastor y Mena Martínez (2003: 184-185), por su parte, ponen de relieve que "las modificaciones y las variantes emplean los mismos procedimientos en su generación pero difieren en las cuestiones pragmáticas, estilísticas y sociolingüísticas derivadas de la motivación del hablante, de los efectos ocasionados y de la institucionalización". Así pues, a las modificaciones ocasionales hay que distinguirlas de las simples variantes estructurales (como todo queda en casa/en familia, irse de/a picos pardos) o las variaciones fraseológicas (meter la pata/metedura de pata). Ambos fenómenos no deberían confundirse, ya que sólo el primero atañe al significado potencial que se actualiza en ciertas UF que sufran alguna deformación de su estructura. 
Dado que el proceso de desautomatización fraseológica se encuadra también dentro de la parcela de la variabilidad, surge una pregunta fundamental: ¿¿i los fenómenos en cuestión, la modificación y la desautomatización, hacen referencia tanto a los cambios en la estructura sintáctica como conceptual de una UF dada, esto significa que son nociones sinónimas y no presentan ningunas discrepancias y solapamientos?

Mena Martínez (2003) hace una puntualización interesante al respecto, afirmando que "en ocasiones los términos modificación y desautomatización han sido utilizados para nombrar la misma cosa. Es cierto que en determinados contextos las palabras modificación y desautomatización pueden utilizarse como sinónimas pero en otros contextos no". Así pues, la autora afirma que algunos lingüistas recurren al término desautomatización refiriéndose a un determinado tipo de modificación ${ }^{3}$.

Cabe recalcar que la investigadora mencionada hace una precisión más, en la que basamos nuestras reflexiones: sólo es posible hablar de desautomatización fraseológica siempre y cuando estemos ante "el proceso que se desencadena en algunas UF cuando se les ha aplicado de forma intencionada cualquier procedimiento de manipulación o modificación creativa. Las modificaciones son los cambios ocasionales o manipulaciones creativas que los hablantes han llevado a cabo en la UF persiguiendo cierta finalidad 4 " (Mena Martínez, 2003).

3 Hasta hoy en día han surgido varias clasificaciones de modificación fraseológica. Por ejemplo, Koller (1977) distinguió entre modificaciones internas y externas, mientras que Burger (1998) habló de modificaciones que afectan a la forma exterior y modificaciones que sólo se refieren al significado. Corpas Pastor y Mena Martínez (2003: 192-193) ampliaron ambas taxonomías y dividieron las modificaciones en dos grupos: 1) modificaciones formales, esto es, cambios no estandarizados que se producen en el interior de la estructura formal de la UF; 2) modificaciones semántico-contextuales y pragmáticas, es decir, cambios que ocurren en relación con otros aspectos que conectan la unidad con su entorno.

4 El subrayado es nuestro. 
Una opinión parecida la comparte también Zuluaga Ospina (2001: 71), quien constata que las alteraciones o modificaciones de las UF, tanto en su estructura interna como en su combinación con otros elementos del discurso, ocasionan una serie de efectos especiales denominados desautomatización. Dicho de otro modo, se trata de la modificación creativa y voluntaria de una UF en un contexto con lo que se persigue un cierto efecto pragmático (expresivo, humorístico, etc.).

Así pues, el fenómeno de la modificación atañe a los cambios ocasionales de la estructura formal y conceptual de las UF, mientras que la desautomatización hace referencia a los efectos semánticos, pragmáticos o estílisticos que dichos cambios ocasionales generan en un contexto dado.:

Todas y cada una de estas alteraciones pueden tener consecuencias semánticas, pero dichas consecuencias no constituyen en sí mismas modificaciones sino que forman parte de los efectos que éstas ocasionan y del proceso creativo que se desencadena conocido como desautomatización (Corpas Pastor y Mena Martínez (2003: 193).

A modo de conclusión parcial podemos señalar que la mayoría de los lingüistas, cuyos estudios giran en torno al fenómeno de desautomatización fraseológica, se pone de acuerdo en que es un proceso que se desencadena en algunas UF cuando se les ha aplicado de forma intencionada u ostensiva cualquier procedimiento de manipulación creativa, bien de índole formal, bien semántica, bien la mezcla de las dos. De ahí que las UF desautomatizadas presenten un alto nivel de creatividad -puesto que son en parte producidas y en parte reproducidas por el hablante-, y sean, como lo expresa Guerra Salas (1997: 303), una "sencilla manifestación de ingenio" o "una intención de originalidad, una complicidad con el lector, un juego compartido que se trastoca y que produce en el lector cierta fruición intelectual".

Así pues, el proceso de desautomatización, que alude a una liberación del lenguaje (Ruiz Gurillo, 1997: 21) y tiene su origen en 
el formalismo ruso ${ }^{5}$, siempre produce una serie de efectos propios en el discurso, es un hecho pragmático y creativo que tiene carácter contextual. Fernández Toledo y Mena Martínez (2007: 192) hablan de tres efectos comunicativos de la desautomatización: 1) crear incertidumbre y provocar interés, 2) establecer inferencias, 3) presentar innovación y romper con los tópicos. Ruiz Gurillo (1997: 23-24) y Timofeeva (2009: 250), por su parte, resaltan que el uso de la UF siempre es un hecho marcado y transgrede algunas máximas conversacionales, puesto que el significado literal del sintagma no se corresponde con el verdadero significado figurado de la unidad. No es de extrañar que cualquier modificación en la UF original rompa doblemente la Máxima de Manera, dado que, como observa Timofeeva (2009: 262):

se elige una manera más compleja de decir algo con el objetivo de conseguir mayores efectos comunicativos [...] por lo cual es de esperar que el oyente convierta su desconcierto inicial en una firmeza sobre la importancia de los efectos comunicativos que le quiera transmitir el hablante.

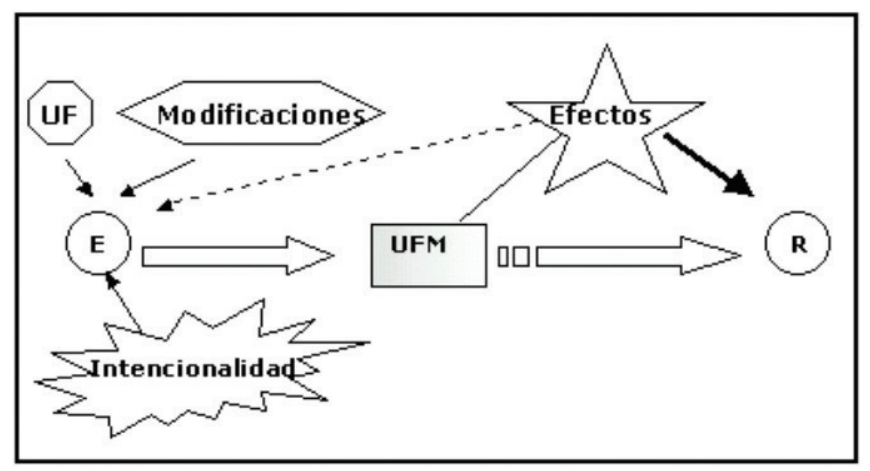

Figura 1. El cuadro ha sido extraído de Mena Martínez (2003)

5 Se trata de los estudios de V. Shklovski, quien opina que la desautomatización alude a un proceso de "crear una impresión máxima", es "el arte como procedimiento o artificio que libere al lenguaje" (cfr. Zuluaga, 1975; Sanmartín Ortí, 2006). 
Así que el proceso de desautomatización tiene mucho en común con el propio acto comunicativo, con la codificación y la descodificación de un mensaje y puede ilustrarse de la manera indicada por Mena Martínez (2003) (véase Figura 1).

Como podemos ver, el emisor (E) recurre a una UF determinada con una cierta intención (cómica, irónica, aclarativa, persuasiva, etc.) y para captar la atención del receptor (R) y realizar el objetivo planteado decide modificar, bien sintáctica, bien semánticamente dicha UF. Esta nueva unidad se convierte en una unidad fraseológica modificada (UFM) y despliega toda una serie de efectos especiales que influyen en el receptor, pero que también son percibidos por el emisor, lo que representa gráficamente una línea discontinua. Dicho de otro modo, las UF en su forma canónica son, en cierto sentido, materia prima, mientras que las modificaciones parecen las herramientas a las que puede recurrir el emisor para producir en el receptor un efecto determinado.

Basándonos en el esquema propuesto por Mena Martínez (2003), vemos claramente que las modificaciones de diversa índole son mecanismos transgresores que pueden conllevar un proceso de desautomatización (cfr. Quepons Ramírez, 2009: 494). Así pues, Mena Martínez (2003) nos da respuesta a una interrogante fundamental, mencionada al principio del presente trabajo: la desautomatización no puede confundirse con la modificación, esto es, ambas nociones no deben tratarse indistintamente, puesto que el primero se refiere a todo el proceso, mientras que el segundo sólo es una parte de él. Al referirse a los dos fenómenos en cuestión, la investigadora (ibídem) hace una observación interesante:

Si el proceso no se completa, no llega al final, tendremos modificación pero no desautomatización. Por tanto, la desautomatización es el resultado de algunas modificaciones, lo cual también implica que pueden darse modificaciones creativas en una determinada UF sin que ésta llegue a alcanzar el estatus de forma desautomatizada. Dicho con otras palabras: puede haber 
modificación sin desautomatización pero no desautomatización sin modificación ${ }^{6}$.

Así pues, la modificación no siempre desencadena la desautomatización, esto es, aunque sea consciente y voluntaria pero no se aparte lo suficiente de la forma base, será solamente una mera modificación y no conllevará un efecto comunicativo perceptible. Al no producir ningún efecto semántico, pragmático o estilístico y de no influir en el oyente -quien es incapaz de inferir todo un conjunto de implicaturas perseguidas por el hablante-, la modificación realizada no puede considerarse creativa e innovadora, sino que es una simple recreación fraseológica. Dicho de otro modo, la UFM, para poder considerarse desautomatizada y verdaderamente creativa, debería cumplir los tres requisitos siguientes:

1) La modificación debe ser una verdadera modificación, es decir, debe representar un cambio ocasional, voluntario e intencionado del hablante;

2) la modificación debe desviarse lo suficiente de la forma originaria para que el cambio pueda ser percibido;

3) la forma base, la unidad originaria, debe ser reconocible y recuperable con ayuda de los elementos conservados e inalterados, o mediante el contexto.

Como observa Mena Martínez (2003) si de los tres requisitos solamente se cumple el primero, estamos ante modificaciones que pueden o no producir la desautomatización. Esta aparecerá únicamente a condición de que se cumplan todos los requisitos mencionados, que forman una especie de continuum. Timofeeva (2009: 254), por su parte, observa que el último requisito parece ser el más importante, puesto que si la forma base no se reconoce, cualquier manipulación resulta inefectiva y pierde todo sentido: "la esencia de la desautomatización fraseológica radica justamente en la recuperación de la unidad original, para que el cambio sea valorado y juzgado en función de los efectos inferenciales que desencadena”. En opinión de Guerrero Salazar (2017: 105), se puede

6 El subrayado es nuestro. 
hablar de una modificación creativa, siempre y cuando la forma canónica de una UF dada siga siendo reconocible.

Además, merece la pena señalar que cualquier cambio en la estructura formal de una UF dada siempre conlleva modificaciones en el plano semántico, mientras que la alteración del significado no necesariamente presupone modificaciones formales (Timofeeva, 2009: 258).

Al abordar la cuestión de la desautomatización fraseológica, nos parece oportuno mencionar que las UF más propensas a presentar este mecanismo creativo y manipulador son, en la mayoría de los casos, locuciones y paremias (cfr. Corpas Pastor, 1996: 234; Quepons Ramírez, 2009: 496-497). Además, existen dos tipos principales de la mencionada desautomatización que dependen del tipo de modificación o alteración empleada, o bien estructural, o bien semántica: la desautomatización formal, que hace referencia a los cambios que aparecen en la estructura formal, interna de la UF (cambios morfológicos, adiciones, supresiones, reducciones, etc.) y la desautomatización semántica, que alude a las modificaciones que parten del potencial semántico de los componentes de una UF dada (juegos de palabras, polisemia fraseológica, intertextualidad, actualización del significado literal y compositivo) ${ }^{7}$.

Al final de nuestras reflexiones teóricas acerca del fenómeno de la desautomatización, conviene subrayar, siguiendo a Mena Martínez (2003), que ciertas modificaciones que desencadenan la desautomatización y, a veces, ciertas desviaciones, pueden convertirse en unidades fraseológicas institucionalizadas y convencionalizadas. No obstante, como pone de relieve García-Page Sánchez (2008: 261), a pesar de que existen creaciones novedosas o recreaciones fraseológicas que no caen en el olvido y consiguen adherirse al léxico mental de los hablantes, nunca reemplazarán la fórmula canónica, ambas conviven temporalmente.

7 Para profundizar en el tema de los varios tipos de desautomatización fraseológica, véanse Corpas Pastor (1996), Fernández Toledo y Mena Martínez (2007), García-Page Sánchez (2008), Timofeeva (2009). 


\section{5.}

\section{Conclusiones}

El objetivo principal del presente artículo, de carácter teórico, ha sido el de contrastar dos fenómenos lingüísticos que gozan de una creciente popularidad entre los investigadores: la modificación y la desautomatización fraseológicas. Hemos intentado demostrar que ambos conceptos, aunque se encuadran dentro de la parcela de variabilidad, no pueden considerarse sinónimos, dado que presentan discrepancias y solapamientos. Tampoco pueden confundirse con las variantes o desviaciones fraseológicas.

No obstante, para que la UF pueda considerarse desautomatizada, no solo tiene que sufrir modificación en su estructura y/o en su significado, sino también producir ciertos efectos comunicativos, percibidos por la persona a la que alcance la unidad desautomatizada. Si no los produce, será simplemente una unidad modificada o "recreada", pero, de ninguna manera, una unidad desautomatizada, intencional y creativa. Así que pueden existir unidades fraseológicas modificadas y no desautomatizadas, pero no lo contrario: la desautomatización siempre se debe a alguna modificación, bien formal, bien semántica.

Conviene señalar que la modificación será eficaz y dará resultados, esto es, desencadenará la desautomatización siempre y cuando el receptor esté familiarizado con la forma canónica de una UF dada (cfr. Quepons Ramírez, 2009: 497). Por consiguiente, cuando la modificación y la forma base no sean perceptibles y recuperables para el receptor, estaremos ante un mecanismo fallido, inefectivo, nada creativo. Será una simple recreación fraseológica.

A modo de conclusión final, merece la pena corroborar que el fenómeno de desautomatización es, sin duda alguna, un proceso complejo, manipulador, voluntario e innovador, que refleja la creatividad lingüística de los hablantes y produce efectos discursivos potentes, es un recurso ostensivo y relevante. La UF desautomatizada rompe con lo normativo, refresca y enriquece el enunciado, puesto que "es, informativamente, más rica, más rica en estímulos, porque interactúan las explicaturas del significado 
idiomático y del significado literal reactivado y las implicaturas intrínsecas en cuanto hecho cultural perteneciente a la memoria colectiva" (García-Page Sánchez, 2008: 262).

\section{Referencias bibliográficas}

Burger, H., Buhofer, A., Sialm, A. (1982), Handbuch der Phraseologie, Berlin y New York: De Gruyter.

Burger, H. (1998), Phraseologie. Eine Einführung am Beispiel des Deutschen, Berlin: Wrich Schmidt Verlag.

Corpas Pastor, G. (1996), Manual de Fraseología Española, Madrid: Gredos.

Corpas Pastor, G., Mena Martínez, F. (2003), “Aproximación a la variabilidad fraseológica de las lenguas alemana, inglesa y española”, ELUA, 17, 181-201.

Dobrovol'skij, D.O. (1988), Phraseologie als Objekt der Universalienlinguistik, Leipzig: Bibliographisches Institut.

Fernández Toledo, P., Mena Martínez, F. (2007), “El papel de la fraseología en el discurso publicitario: sugerencias para un análisis multidisciplinar", Pensar la publicidad. Vol. 1, №. 1, 181-198.

García-Page Sánchez, M. (1989), “Sobre los procesos de deslexicalización en las expresiones fijas”, Español Actual, 52, 59-79.

García-Page Sánchez, M. (2008), Introducción a la fraseología española, Barcelona: Anthropos.

González Calvo, J. M. (2007), "Unidades fraseológicas y creatividad: propuesta de neología fraseológica”, en J. Cuartero Otal, J. y M. Emsel (eds.), Vernetzungen. Bedeutung in Word, Satz und Text. Festschrift für Gerd Wotjak zum 65. Geburstag. Vol. 1, Frankfurt, Berlín: Peter Lang, 199-208.

Guerra Salas, L. (1997), "La ruptura de la frase hecha en el lenguaje periodístico y publicitario", Paremia, 6, 301-306.

Guerrero Salazar, S. (2017), "La desautomatización de las unidades fraseológicas en los titulares deportivos", Verba, Vol. 44, 99-131

Koller, W. (1977), Redensarten. Linguistische Aspekte, Vorkommensanalysen Sprachspiel. Reihe Germanistische Linguistik 5, Tübingen: Niemeyer.

Martí Sánchez, M. (2014), "Motivación y arbitrariedad en la desautomatización fraseológica (sobre sus implicaciones 
didácticas)", en P. Mogorrón Huerta y S. Mejri (eds.), Fijación, Traducción, Variación y Desautomatización, Universidad de Alicante: Servicio de Publicaciones, 89-115.

Mena Martínez, F. (2003), "En torno al concepto de desautomatización fraseológica: aspectos básicos”, Tonos digital: Revista electrónica de estudios filológicos. N.o 5 [en línea] <http://www. um.es/tonosdigital/znum5/estudios/H-Edesautomatizacion. htm>, [fecha de consulta: 28.01.2019].

Quepons Ramírez, C. (2009), "El proceso de desautomatización en la fraseología española: un acercamiento", en A. Marín Marín y D. V. Heffington (eds.), Memorias del V Foro de Estudios en Lenguas Internacional (FEL 2009), 492-506.

Ruiz Gurillo, L. (1997), "Relevancia y fraseología: la desautomatización en la conversación coloquial”, Español actual, 68, 21-30.

Ruiz Gurillo, L. (2001), Las locuciones en español actual, Madrid: Arco Libros.

Sanmartín Ortí, P. (2006), La finalidad poética en el formalismo ruso: el concepto de desautomatización [en línea] < https:// eprints.ucm.es/7496/1/T29437.pdf >, [fecha de consulta: 29.01.2019].

Timofeeva, L. (2009), "La desautomatización fraseológica: un recurso para crear y divertir”, Investigaciones Lingüisticas en el siglo XXI, 249-271.

Zuluaga Ospina, A. (1975), "La fijación fraseológica”, Thesaurus, XXX, 225-248.

Zuluaga Ospina, A. (2001), "Análisis y traducción de unidades fraseológicas desautomatizadas", PhiN 16/2001, 67-83, [en línea] http://web.fu-berlin.de/phin/phin16/p16t5.htm, [fecha de consulta: 29.01.2019]. 